International Journal of Engineering \& Technology, $7(3.29)(2018) 39-45$
SPC
International Journal of Engineering \& Technology
Website: www.sciencepubco.com/index.php/IJET
Research paper

\title{
Analysis of selected parking spaces in medium sized cities of tamil nadu
}

\author{
Dr. R. Prasannakumar ${ }^{1 *}$, Akella. Naga sai baba ${ }^{2}$, V. Ranjith Kumar ${ }^{2}$, Sudharsan.R ${ }^{3}$ \\ ${ }^{1}$ Professor, Malla Reddy Engineering College,(Autonomous) Kompally \\ ${ }^{2}$ Assistant Professor, Malla Reddy Engineering College,(Autonomous) Kompally \\ ${ }^{3}$ Formerly under Graduate students at SASTRA University, Thanjavur \\ *Corresponding author E-mail: prasanna1968@gmail.com
}

\begin{abstract}
The present study aims to analyze the conditions of identified parking lots in two medium sized cities of Tamil Nadu, namely Tiruchirapalli and Thanjavur, and suggest possible measures for improvement. Methods like parking space inventory survey, cordon count and parking usage control by patrol were used for data collection. The number of vehicles occupying the parking spaces at a specific period of time was determined. This count was taken at regular intervals over a time period spread over 9 am to $6 \mathrm{pm}$, in three sessions. The data collected was then analysed and peak values of the numbers of different types of vehicles was identified. Observations of the prevalent topographical conditions at the study locations were made and a few suggestions pertaining to maintenance, enhancement, improved efficiency and tariff were provided.
\end{abstract}

Keywords: Parking Space Inventory; Tiruchirappalli; Thanjavur; Strategies; Patrol; Tariff; Parking Lots.

\section{Introduction}

\section{Introduction and literature review}

Parking is one among the serious problems which the urban planner and traffic engineer face. So suitable measures aimed at the optimum usage of available space should be implemented. Before such measures can be taken, collection of data through surveys is mandatory. The types of surveys adopted for this study include parking space inventory survey, parking usage survey by patrol and cordon count. In parking space inventory survey, the study location was delineated and subdivided into parts, to make the job easy. Different types of data regarding the parking load and topography are collected. In parking usage survey by patrol, the study area was patrolled at regular intervals, thereby counting the number of vehicles parked at a particular instant. This reading is taken at regular intervals and tabulated, thereby identifying the extent of usage. The Cordon count method keeps track of the number of vehicles entering and leaving the parking area, thereby the count at a particular instant can be known. The study was undertaken at three locations, namely Palpannai and Super Bazaar in Tiruchirappalli City and the parking space near Big Temple in Thanjavur City. The data collection was taken up in three sessions per day, readings being noted at every 15 minute interval. Peak values of parking load were identified upon analysis and suitable recommendations and corrective measures were proposed after correlation with the standard codebook, IRC SP 12 2015. The types of vehicles being parked at a location, frequency of arrival of vehicles, duration of parking, topographical conditions and dimensions of the parking space etc. were all considered during this study.

\section{Methodology}

- Selection of study locations

- Feasibility study at the selected locations

- Collection of data using parking surveys

- Analysis of data

- Identification of peak parking load

- Suggesting suitable recommendations upon suitable correlation with IRC SP 122015

\subsection{Study area characteristics}

Three locations were selected for analysis. The first location was Super bazaar car parking space, Tiruchirappalli city (10.824974N, 78.695101E).Second location that was selected for analysis was Palpannai two wheeler parking near Palpannai bus stand and the third parking was Thanjavur Brihadeeshwara temple parking $(10.782953 \mathrm{~N}, 79.134311 \mathrm{E})$. Tiruchirappalli district is located along the banks of the Cauvery River, at the heart of Tamil Nadu state. The latitude coordinates of the district are $10 \mathrm{o} 47^{\prime} 40.56^{\prime \prime} \mathrm{N}$ 78041'6"E.It is bound by Salem district in the north and Thanjavur district in the south. It is also bordered by Perambalur, Madurai, Ariyalur, Pudukkottai and Sivagangai districts. The latest census recorded a population count of $2,722,290$, which has a great bearing on the parking volume.

\subsection{Identification of study sections}

Several locations were considered for analysis of which three locations were selected, namely Super bazaar car parking, Palpannai two wheeler parking and Tanjore big temple parking. The main rea- 
son behind the selection of these parking spaces was existing condition of the parking space, deviation from the recommendations given by the latest IRC codes SP 12-2015, occupancy rate of the parking space and based on the location characteristics.
Parking space inventory survey was conducted at selected locations in and around Tiruchirappalli and the following data was obtained:

\subsection{Data collection}

Table 1: Super Bazaar off Street Parking Summary SLOT 1: 9.15-11.15am

\begin{tabular}{|c|c|c|c|c|c|c|c|}
\hline \multirow[t]{3}{*}{ Sl. No } & \multirow[t]{3}{*}{ Time Interval } & \multirow[t]{3}{*}{ Total Area $\left(\mathrm{M}^{2}\right)$} & \multicolumn{5}{|c|}{ Type of Vehicles Parked: } \\
\hline & & & \multicolumn{2}{|c|}{ 2-Wheelers } & \multirow{2}{*}{ 3-Wheeelers } & \multicolumn{2}{|c|}{ 4-Wheelers } \\
\hline & & & Motorised & Non- Motorised & & Cars & Other Than Cars \\
\hline 1 & $9.15-9.30$ & 3398 & 3 & 0 & 0 & 18 & 0 \\
\hline 2 & $9.30-9.45$ & 3398 & 2 & 0 & 2 & 26 & 0 \\
\hline 3 & $9.45-10 . .00$ & 3398 & 1 & 0 & 1 & 30 & 1 \\
\hline 4 & $10.00-10.15$ & 3398 & 1 & 0 & 4 & 36 & 2 \\
\hline 5 & $10.15-10.30$ & 3398 & 3 & 0 & 5 & 41 & 2 \\
\hline 6 & $10.30-10.45$ & 3398 & 7 & 0 & 3 & 45 & 2 \\
\hline 7 & $10.45-11.00$ & 3398 & 11 & 0 & 6 & 49 & 2 \\
\hline 8 & $11.00-11.15$ & 3398 & 12 & 0 & 4 & 54 & 3 \\
\hline
\end{tabular}

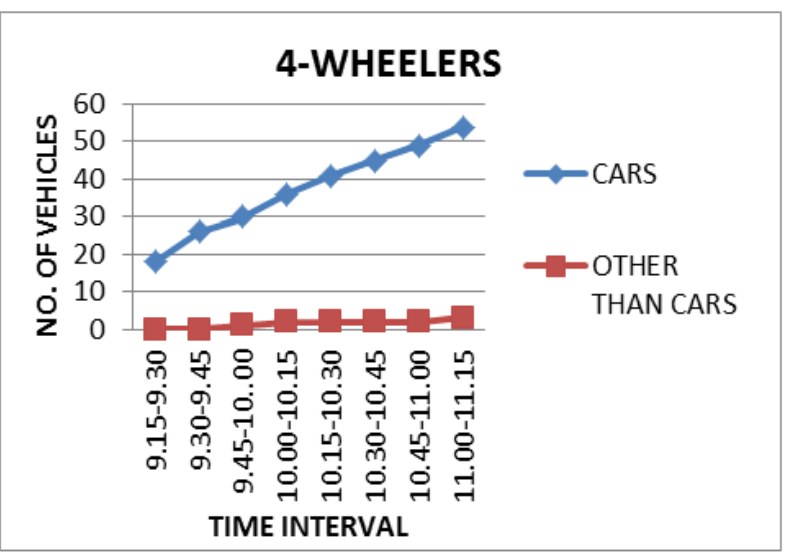

Fig. 1: Parking Accumulation Curve (4-Wheelers) - Slot 1.

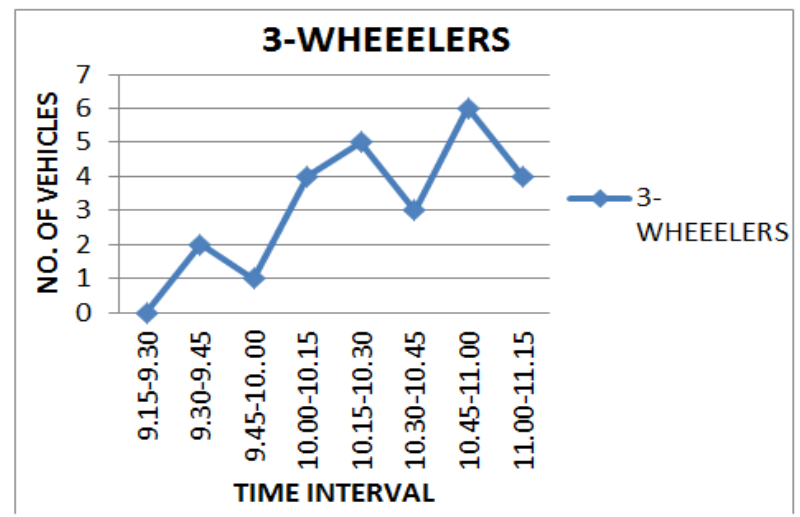

Fig. 3: Parking Accumulation Curve (3-Wheelers) - Slot 1.

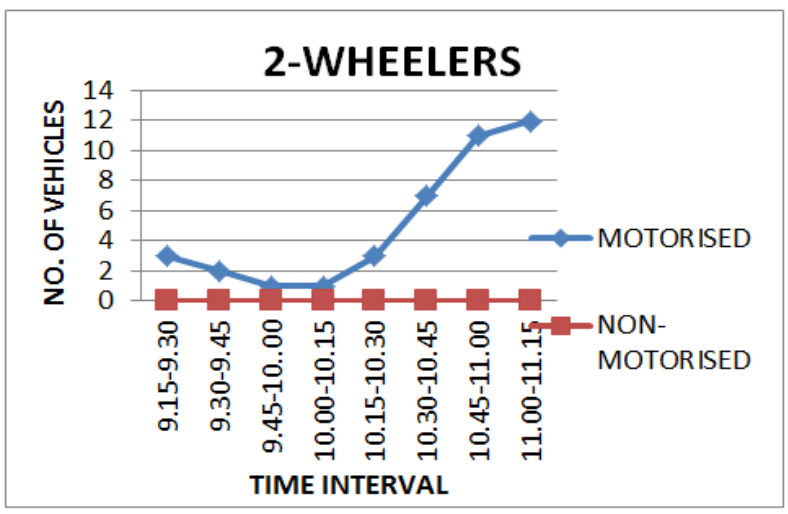

Fig. 2: Parking Accumulation Curve (2-Wheelers) - Slot 1.

Table 2: Super Bazaar: Off Street Parking Summary - SLOT 2: 12.30-2.30pm

\begin{tabular}{|c|c|c|c|c|c|c|c|}
\hline Sl.No & Time Interval & Total Area $\left(\mathrm{M}^{2}\right)$ & Type of Vel & Parked: & & & \\
\hline & & & $\begin{array}{l}\text { 2-Wheelers } \\
\text { Motorised }\end{array}$ & Non- Motorised & 3-Wheeelers & $\begin{array}{l}\text { 4-Wheelers } \\
\text { Cars }\end{array}$ & Other Than Cars \\
\hline 1 & $12.30-12.45$ & 3398 & 6 & 0 & 8 & 87 & 3 \\
\hline 2 & $12.45-1.00$ & 3398 & 7 & 0 & 7 & 74 & 3 \\
\hline 3 & $1.00-1.15$ & 3398 & 15 & 0 & 8 & 88 & 3 \\
\hline 4 & $1.15-1.30$ & 3398 & 16 & 0 & 9 & 100 & 3 \\
\hline 5 & $1.30-1.45$ & 3398 & 10 & 0 & 5 & 87 & 2 \\
\hline 6 & $1.45-2.00$ & 3398 & 11 & 0 & 6 & 89 & 3 \\
\hline 7 & $2.00-2.15$ & 3398 & 8 & 0 & 6 & 91 & 2 \\
\hline 8 & $2.15-2.30$ & 3398 & 7 & 0 & 4 & 87 & 2 \\
\hline
\end{tabular}




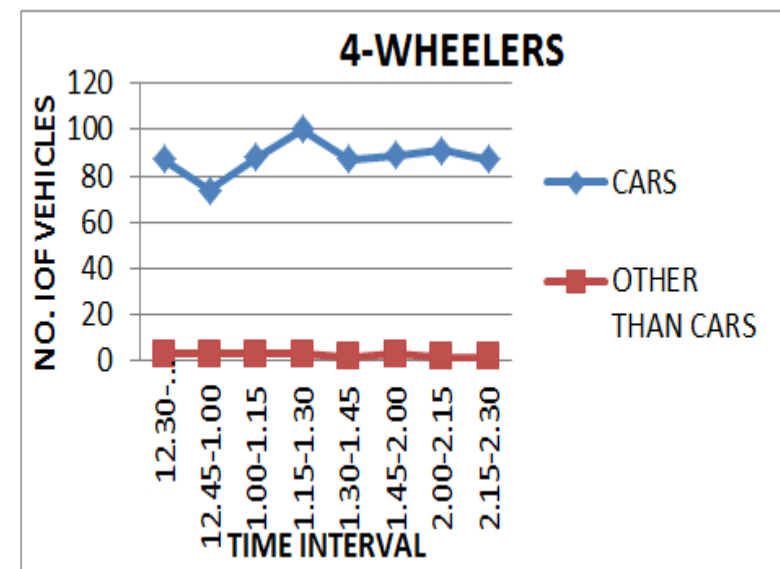

Fig. 5: Parking Accumulation Curve (Cars)-Slot 2 (12.30-2.30).

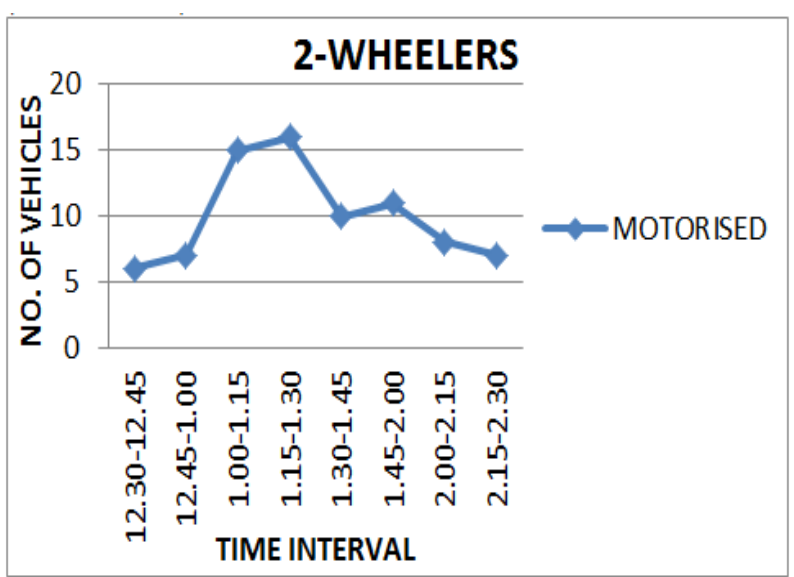

Fig. 6: Parking Accumulation Curve (Two Wheelers)-Slot 2 (12.30-2.30).

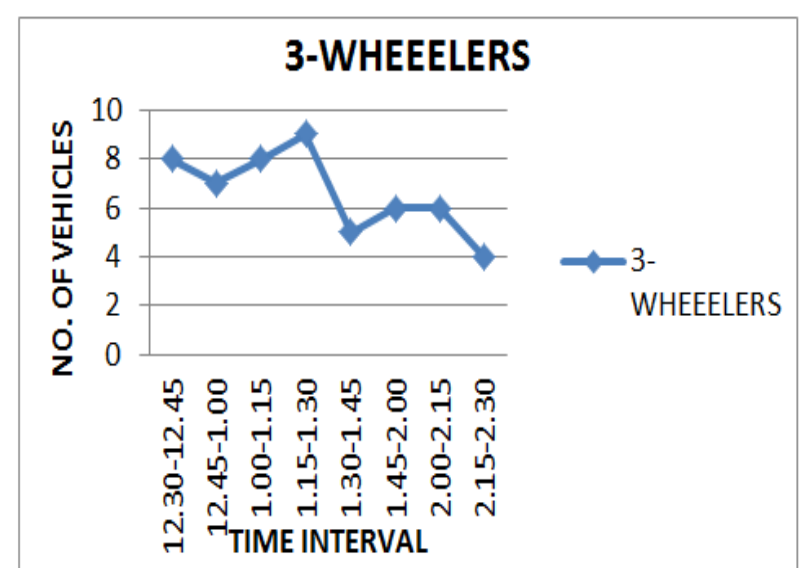

Fig. 7: Parking Accumulation Curve (Three Wheelers)-Slot 2 (12.30-2.30).

Table 3: Super Bazaar: Off Street Parking Summary - SLOT 3: 4.00-6.00pm

\begin{tabular}{|c|c|c|c|c|c|c|c|}
\hline S1.No & Time Interval & Total Area $\left(\mathrm{M}^{2}\right)$ & Type of Veh & arked: & & & \\
\hline & & & $\begin{array}{l}\text { 2-Wheelers } \\
\text { Motorized }\end{array}$ & Non- Motorized & 3-Wheeelers & $\begin{array}{l}\text { 4-Wheelers } \\
\text { Cars }\end{array}$ & Other Than Cars \\
\hline 1 & $4.00-4.15$ & 3398 & 5 & 0 & 7 & 81 & 1 \\
\hline 2 & $4.15-4.30$ & 3398 & 7 & 0 & 3 & 82 & 4 \\
\hline 3 & $4.30-4.45$ & 3398 & 7 & 0 & 3 & 82 & 4 \\
\hline 4 & $4.45-5.00$ & 3398 & 6 & 0 & 1 & 88 & 4 \\
\hline 5 & $5.00-5.15$ & 3398 & 5 & 0 & 2 & 81 & 4 \\
\hline 6 & $5.15-5.30$ & 3398 & 6 & 0 & 3 & 72 & 3 \\
\hline 7 & $5.30-5.45$ & 3398 & 5 & 0 & 5 & 71 & 2 \\
\hline 8 & $5.45-6.00$ & 3398 & 5 & 0 & 4 & 73 & 2 \\
\hline
\end{tabular}

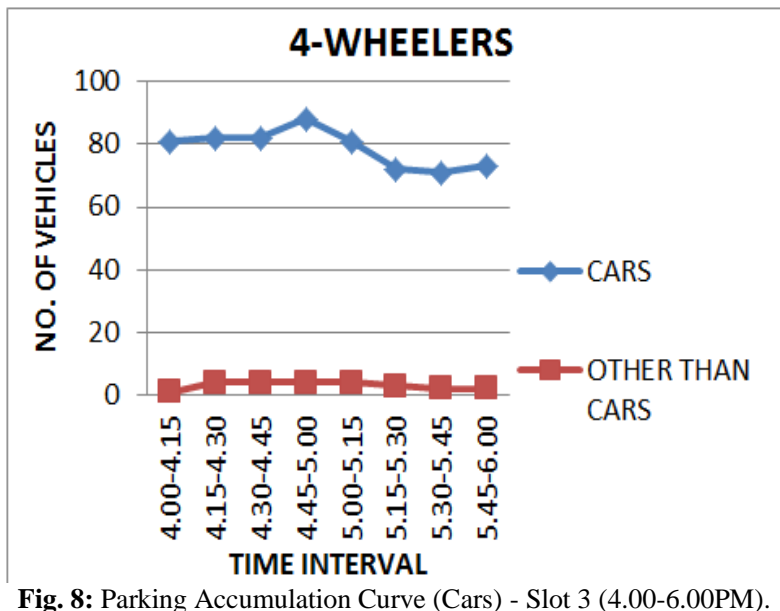

Fig. 8: Parking Accumulation Curve (Cars) - Slot 3 (4.00-6.00PM).

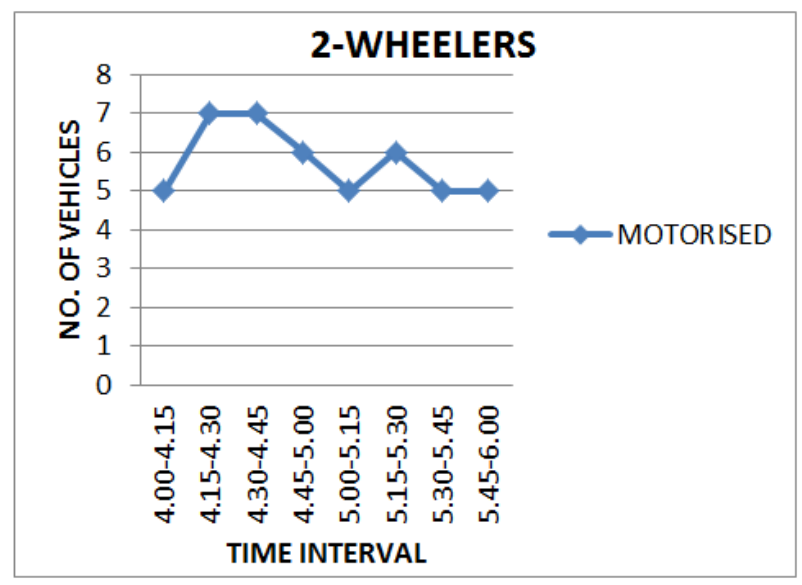

Fig. 9: Parking Accumulation Curve (Two Wheelers) - Slot 3 (4.006.00PM). 


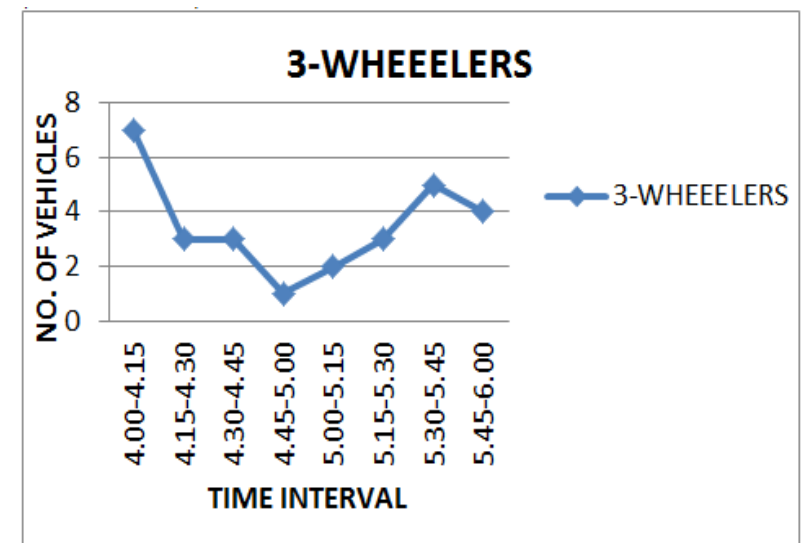

Fig. 10: Parking Accumulation Curve (three Wheelers) - Slot 3 (4.00$6.00 \mathrm{pm})$.

Table 4: Palpannai: Off Street Parking Summary - SLOT1: 9.15AM-11.15AM

\begin{tabular}{|c|c|c|c|c|c|c|c|}
\hline \multirow[t]{3}{*}{ Sl.No } & \multirow[t]{3}{*}{ Time Interval } & \multirow[t]{3}{*}{ Total Area $\left(\mathrm{M}^{2}\right)$} & \multicolumn{5}{|c|}{ Type of Vehicles Parked: } \\
\hline & & & \multicolumn{2}{|c|}{ 2-Wheelers } & \multirow{2}{*}{ 3-Wheeelers } & \multicolumn{2}{|c|}{ 4-Wheelers } \\
\hline & & & Motorised & Non- Motorised & & Cars & Other Than Cars \\
\hline 1 & $9.15-9.30$ & 372 & 128 & 4 & 0 & 0 & 0 \\
\hline 2 & $9.30-9.45$ & 372 & 132 & 4 & 0 & 0 & 0 \\
\hline 3 & $9.45-10 . .00$ & 372 & 140 & 4 & 0 & 0 & 0 \\
\hline 4 & $10.00-10.15$ & 372 & 140 & 4 & 0 & 0 & 0 \\
\hline 5 & $10.15-10.30$ & 372 & 147 & 4 & 0 & 0 & 0 \\
\hline 6 & $10.30-10.45$ & 372 & 149 & 4 & 0 & 0 & 0 \\
\hline 7 & $10.45-11.00$ & 372 & 151 & 4 & 0 & 0 & 0 \\
\hline 8 & $11.00-11.15$ & 372 & 153 & 4 & 0 & 0 & 0 \\
\hline
\end{tabular}

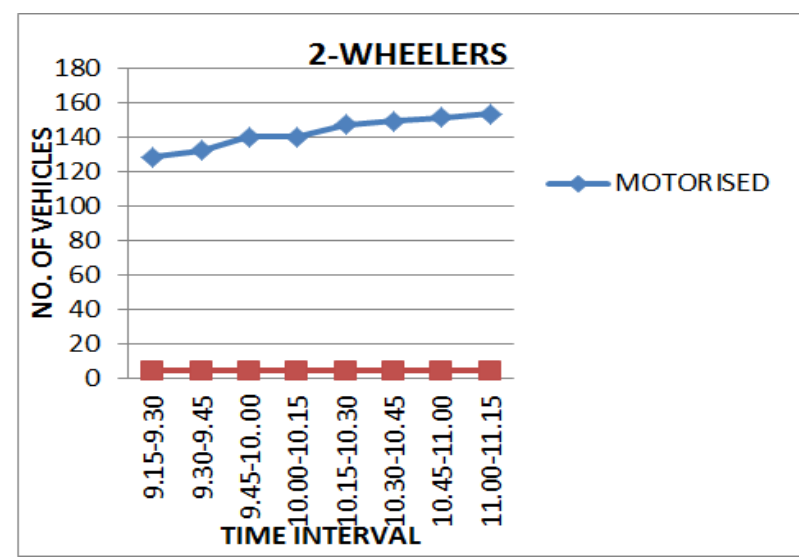

Fig. 10: Parking Accumulation Curve (Two Wheelers) - SLOT 1.

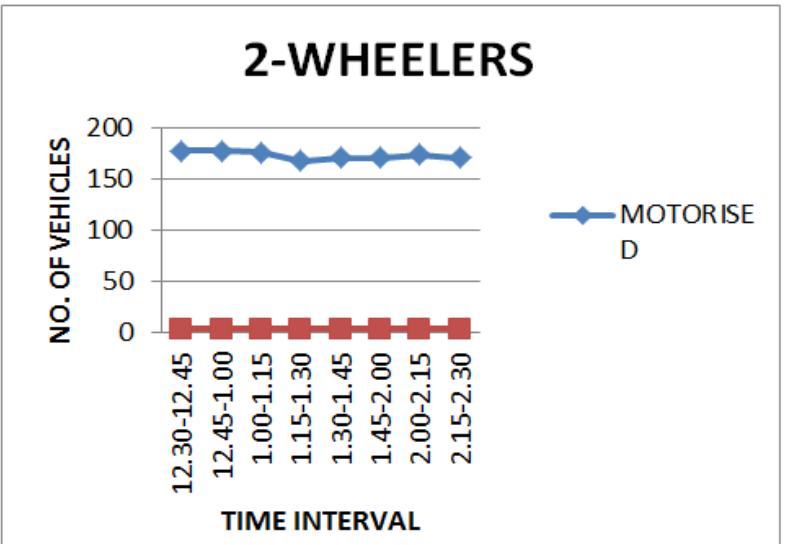

Fig.11: Parking Accumulation Curve (Two Wheelers)-Slot 2 (12.302.30pm).

Table 5: Palpannai: Off Street Parking Summary - SLOT 2: 12.30-2.30.

\begin{tabular}{|c|c|c|c|c|c|c|c|}
\hline \multirow[t]{2}{*}{ Sl.No } & \multirow[t]{2}{*}{ Time Interval } & \multirow[t]{2}{*}{ Total Area (M) } & \multicolumn{5}{|c|}{ Type of Vehicles Parked: } \\
\hline & & & $\begin{array}{l}\text { 2-Wheelers } \\
\text { Motorized }\end{array}$ & Non- Motorized & 3-Wheeelers & $\begin{array}{l}\text { 4-Wheelers } \\
\text { Cars }\end{array}$ & Other Than Cars \\
\hline 1 & $12.30-12.45$ & 372 & 178 & 4 & 0 & 0 & 0 \\
\hline 2 & $12.45-1.00$ & 372 & 178 & 4 & 0 & 0 & 0 \\
\hline 3 & $1.00-1.15$ & 372 & 176 & 4 & 0 & 0 & 0 \\
\hline 4 & $1.15-1.30$ & 372 & 168 & 4 & 0 & 0 & 0 \\
\hline 5 & $1.30-1.45$ & 372 & 171 & 4 & 0 & 0 & 0 \\
\hline 6 & $1.45-2.00$ & 372 & 171 & 4 & 0 & 0 & 0 \\
\hline 7 & $2.00-2.15$ & 372 & 174 & 4 & 0 & 0 & 0 \\
\hline 8 & $2.15-2.30$ & 372 & 171 & 4 & 0 & 0 & 0 \\
\hline
\end{tabular}

Table 6: Palpannai: off Street Parking Summary - SLOT 3: 4.00-6.00pm

\begin{tabular}{|c|c|c|c|c|c|c|c|}
\hline \multirow[t]{2}{*}{ Sl.No } & \multirow[t]{2}{*}{ Time Interval } & \multirow[t]{2}{*}{ Total Area $\left(\mathrm{M}^{2}\right)$} & \multicolumn{5}{|c|}{ Type of Vehicles Parked: } \\
\hline & & & $\begin{array}{l}\text { 2-Wheelers } \\
\text { Motorised }\end{array}$ & Non- Motorised & 3-Wheeelers & $\begin{array}{l}\text { 4-Wheelers } \\
\text { Cars }\end{array}$ & Other Than Cars \\
\hline 1 & $4.00-4.15$ & 372 & 166 & 4 & 0 & 0 & 0 \\
\hline 2 & $4.15-4.30$ & 372 & 166 & 4 & 0 & 0 & 0 \\
\hline 3 & $4.30-4.45$ & 372 & 165 & 4 & 0 & 0 & 0 \\
\hline 4 & $4.45-5.00$ & 372 & 164 & 4 & 0 & 0 & 0 \\
\hline 5 & $5.00-5.15$ & 372 & 161 & 4 & 0 & 0 & 0 \\
\hline 6 & $5.15-5.30$ & 372 & 151 & 4 & 0 & 0 & 0 \\
\hline 7 & $5.30-5.45$ & 372 & 141 & 4 & 0 & 0 & 0 \\
\hline 8 & $5.45-6.00$ & 372 & 115 & 4 & 0 & 0 & 0 \\
\hline
\end{tabular}




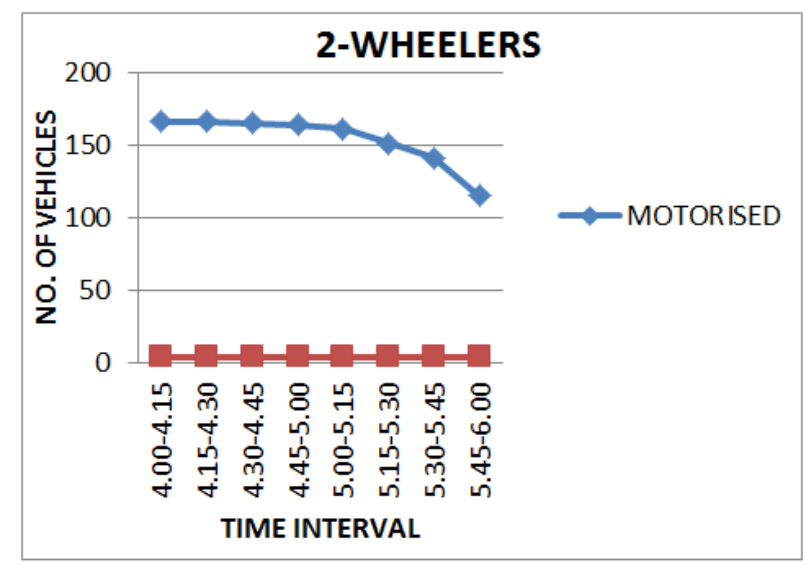

Fig. 12: Parking Accumulation Curve (two Wheelers) -Slot 2 (4.00$6.00 \mathrm{pm})$.

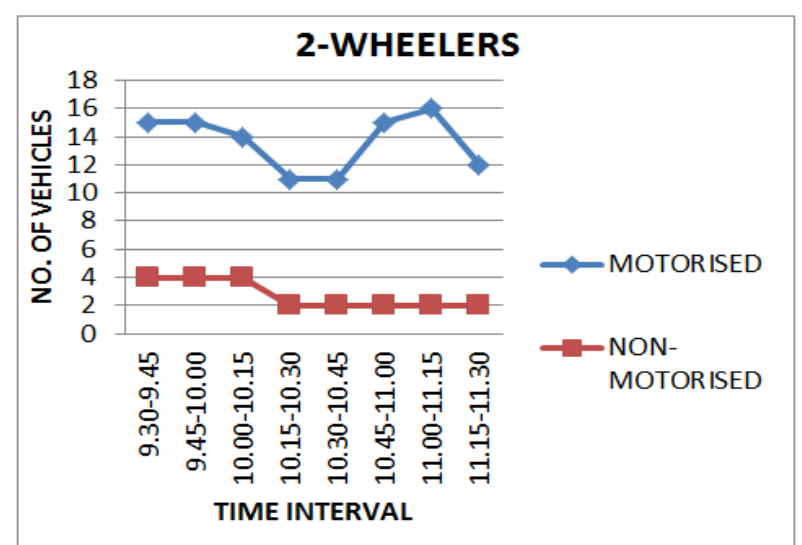

Fig. 14: Parking Accumulation Curve (2-Wheelers) - Slot 1(9.30-11.30).

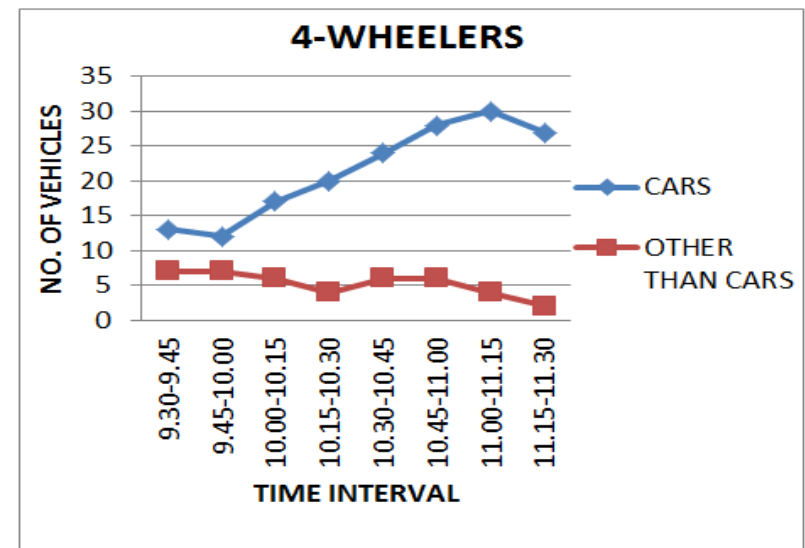

Fig. 13: Parking Accumulation Curve (Four Wheelers) - Slot 1(9.30-11.30).

Table 7: Thanjavur: Off Street Parking Summary - Slot1: 9.15am-11.15am

\begin{tabular}{|c|c|c|c|c|c|c|c|}
\hline \multirow[t]{3}{*}{ S1.No } & \multirow[t]{3}{*}{ Time Interval } & \multirow[t]{3}{*}{ Total Area $\left(\mathrm{M}^{2}\right)$} & \multicolumn{5}{|c|}{ Type of Vehicles Parked: } \\
\hline & & & \multicolumn{2}{|c|}{ 2-Wheelers } & \multirow[t]{2}{*}{ 3-Wheeelers } & \multicolumn{2}{|c|}{ 4-Wheelers } \\
\hline & & & Motorised & Non- Motorised & & Cars & Other Than Cars \\
\hline 1 & $9.30-9.45$ & 4850 & 15 & 4 & 0 & 13 & 2 \\
\hline 2 & $9.45-10.00$ & 4850 & 15 & 4 & 0 & 12 & 2 \\
\hline 3 & $10.00-10.15$ & 4850 & 14 & 4 & 0 & 17 & 2 \\
\hline 4 & $10.15-10.30$ & 4850 & 11 & 2 & 0 & 20 & 1 \\
\hline 5 & $10.30-10.45$ & 4850 & 11 & 2 & 1 & 24 & 2 \\
\hline 6 & $10.45-11.00$ & 4850 & 15 & 2 & 0 & 28 & 2 \\
\hline 7 & $11.00-11.15$ & 4850 & 16 & 2 & 0 & 30 & 2 \\
\hline 8 & $11.15-11.30$ & 4850 & 12 & 2 & 0 & 27 & 1 \\
\hline
\end{tabular}

Table 8: Thanjavur: Off Street Parking Summary - Slot2: 12.30pm-2.30pm.

\begin{tabular}{|c|c|c|c|c|c|c|c|}
\hline \multirow[t]{2}{*}{ S1.No } & \multirow[t]{2}{*}{ Time Interval } & \multirow[t]{2}{*}{ Total Area $\left(\mathrm{M}^{2}\right)$} & \multicolumn{5}{|c|}{ Type of Vehicles Parked: } \\
\hline & & & $\begin{array}{l}\text { 2-Wheelers } \\
\text { Motorised }\end{array}$ & Non- Motorised & 3-Wheeelers & $\begin{array}{l}\text { 4-Wheelers } \\
\text { Cars }\end{array}$ & Other Than Cars \\
\hline 1 & $12.30-12.45$ & 4850 & 14 & 2 & 0 & 24 & 7 \\
\hline 2 & $12.45-1.00$ & 4850 & 16 & 2 & 0 & 22 & 7 \\
\hline 3 & $1.00-1.15$ & 4850 & 15 & 2 & 0 & 19 & 6 \\
\hline 4 & $1.15-1.30$ & 4850 & 13 & 1 & 0 & 19 & 4 \\
\hline 5 & $1.30-1.45$ & 4850 & 13 & 0 & 0 & 15 & 6 \\
\hline 6 & $1.45-2.00$ & 4850 & 11 & 0 & 0 & 15 & 6 \\
\hline 7 & $2.00-2.15$ & 4850 & 11 & 0 & 0 & 11 & 4 \\
\hline 8 & $2.15-2.30$ & 4850 & 10 & 0 & 0 & 10 & 2 \\
\hline
\end{tabular}




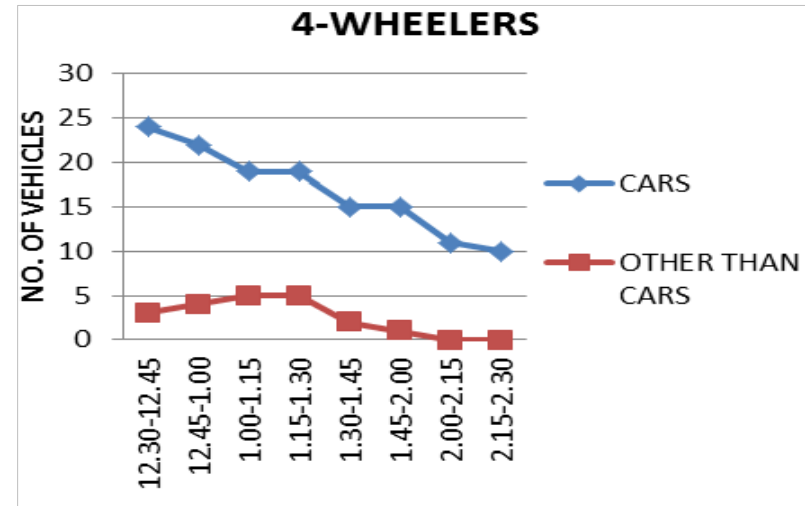

TIME INTERVAL

Fig. 15: Parking Accumulation Curve (four Wheelers) - Slot 2 (12.302.30pm).

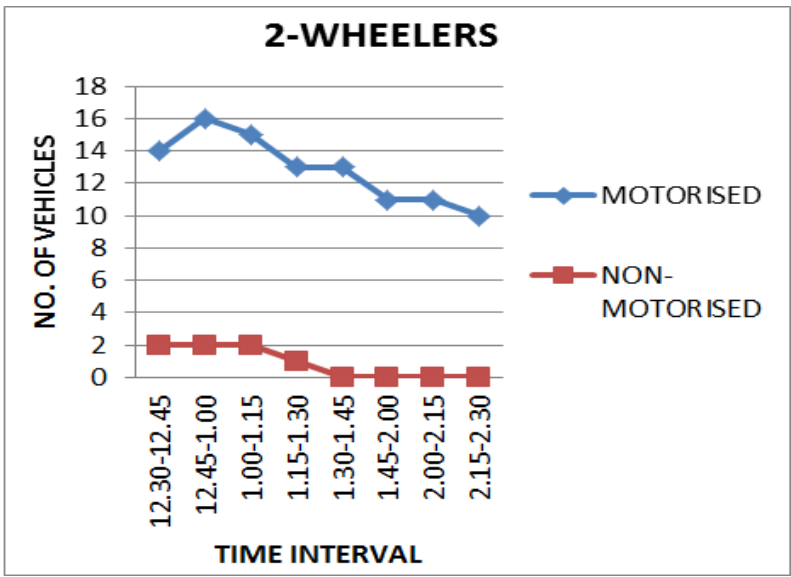

Fig. 16: Parking Accumulation Curve (two Wheelers) - Slot 2 (12.30$2.30 \mathrm{pm})$.

\begin{tabular}{|c|c|c|c|c|c|c|c|}
\hline \multirow[t]{3}{*}{ S1.No } & \multirow[t]{3}{*}{ Time Interval } & \multirow[t]{3}{*}{ Total Area $\left(\mathrm{M}^{2}\right)$} & \multicolumn{5}{|c|}{ Type of Vehicles Parked: } \\
\hline & & & \multicolumn{2}{|l|}{ 2-Wheelers } & \multirow{2}{*}{ 3-Wheeelers } & \multicolumn{2}{|c|}{ 4-Wheelers } \\
\hline & & & Motorised & Non- Motorised & & Cars & Other Than Cars \\
\hline 1 & $4.00-4.15$ & 4850 & 9 & 0 & 0 & 26 & 4 \\
\hline 2 & $4.15-4.30$ & 4850 & 8 & 0 & 0 & 26 & 4 \\
\hline 3 & $4.30-4.45$ & 4850 & 5 & 1 & 0 & 30 & 2 \\
\hline 4 & $4.45-5.00$ & 4850 & 7 & 1 & 0 & 31 & 2 \\
\hline 5 & $5.00-5.15$ & 4850 & 13 & 1 & 0 & 30 & 3 \\
\hline 6 & $5.15-5.30$ & 4850 & 13 & 1 & 0 & 26 & 3 \\
\hline 7 & $5.30-5.45$ & 4850 & 12 & 2 & 0 & 27 & 5 \\
\hline 8 & $5.45-6.00$ & 4850 & 12 & 2 & 0 & 25 & 6 \\
\hline
\end{tabular}

\subsection{Analysis and results}

Parking demand was found and parking accumulation curve was plotted between the numbers of vehicles in the parking lot vs. time interval. The observations made in the selected sites during the survey are as follows:

Super Bazaar:

i) Undulations were observed over the surface of the parking space i.e. uneven flooring was observed.

ii) It was observed that $25 \%$ of the parking space was used for dumping garbage.

iii) Parking space does not possess any facility to separate vehicular area and passage space for pedestrians.

iv) The parking space doesn't have a proper bay system thereby the parking space for each vehicle doesn't satisfy the dimensions prescribed by IRC.

v) Access aisle between 2parked spaces was observed to vary between $0.9 \mathrm{~m}$ to $1.2 \mathrm{~m}$.

vi) vi. Parking space does not possess proper sign boards.

vii) vii. It is a free parking space.

Palpannai:

i) The place where the concerned parking space is located is an area of very high vehicular utilisation and the area also act as

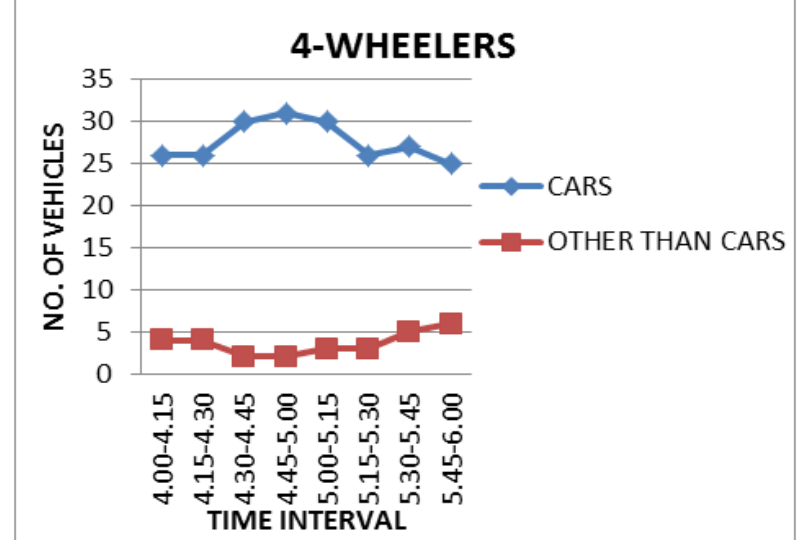

Fig.17: Parking Accumulation Curve (4 Wheelers) - Slot 3 (4.00-6.00pm).

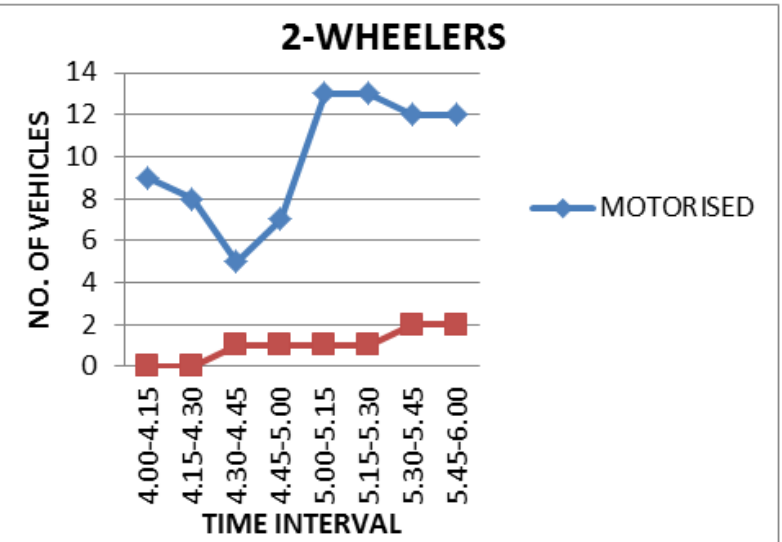

Fig. 18: Parking Accumulation Curve (2 Wheelers) - Slot 3 (4.00-6.00pm).

a junction point connecting certain other prime areas of Trichy city.

ii) Parking space is insufficient corresponding to the demand for parking and hence spill over of vehicles outside the parking space was observed.

iii) Similar to the other parking space mentioned previously, this site also lacks a proper bay allocation system.

iv) It can be observed from the graphs that parking space is exclusively utilised only for parking two wheelers alone, this causes an inconvenient situation for other types of vehicle users in parking their vehicles.

v) Parking space possesses a manual tariff system which proves less efficient during the time of peak hours.

Brahadeeshwarar Temple, Thanjavur:

i) Lack of proper roofing system in the parking space.

ii) Occasional dumping of garbage and lack of cleanliness.

iii) Insufficient space for people to walk within the parking space.

iv) From observations of general trends, it is found that this parking space has peak load during festival times, and the load during other times is not that much. So the space should be made efficient enough to handle the sudden peak load 


\subsection{Suggestions to improve the efficiency of the parking lot}

Following are the recommendations which can be implemented in all the three parking lots:

i) Very concrete flooring with slip resistant tiles can be constructed so as to provide a levelled parking surface with sufficient friction.

ii) Parking space should be exclusively used for vehicular parking only ensuring $100 \%$ utilisation of the space and therefore existing garbage dumping should be cleared and strict enforcement of penalties should be incorporated to avoid future dumping.

iii) Usage of precast wheel stops and a passage of $0.90 \mathrm{~m}$ should be created for the pedestrians to walk through after parking their vehicle so that interruption of people in the vehicular area can be avoided thus preventing mishaps while parking.

iv) Installation of sign boards is mandatory so as to give a clear idea for the driver to park their vehicle in the parking bays and this avoids unnecessary confusions and traffic while parking. Efficiency and utilisation of the parking space is improved.

v. Since the parking space is surrounded by shopping complex and other commercial centres, it is advisable to restrict the utilisation of space only by cars and not by any other vehicles

v) 45, 60 AND 90degree angle bay system can be implemented as per IRC SP12-2015 at the site for effective utilisation of the parking space without any congession, traffic and other problems

vi) Bay system thus introduced must possess an area of 2036sq.m for each bay as prescribed by IRC SP12-2015

vii) Dimensions suggested by IRC SP12-2015 for each parking bay are as follows: Width of the parking bay- $3.60 \mathrm{~m}(\mathrm{~min})$ to $3.90 \mathrm{~m}$ (recommended) Length of the parking bay- $5.20 \mathrm{~m}$ to $5.50 \mathrm{~m}$

viii) Access aisle of $1.2 \mathrm{~m}$ width should be incorporated between two parking bays

ix) Since PALPANNAI is a prime area in the city of Tiruchirappalli with a heavy traffic flow the existing parking space may be expanded and can be utilised for parking of other type of vehicles in addition to two wheelers.

x) Parking space can be extended over the barren land behind the existing parking space so as to accommodate more vehicles thus preventing such spill over of vehicles outside the parking space

\section{Conclusion}

Real time data was obtained by conducting field survey to understand the occupancy level of the parking space at all the study locations. Based on the analysis of data it was found that the parking spaces were not utilised to the maximum possible extent in a majority of cases and in a few cases were not capable and efficient enough to meet the heavy demand. In the super bazaar parking space, the peak parking load occurred in the second slot that is between $12.30 \mathrm{pm}$ and $1.30 \mathrm{pm}$. Hence possible solutions were suggested. It was also realised that with such a demand for parking spaces being generated continuously, suitable enforcements and regulations need to be periodically included in the system, to reduce congestion problems and for safe and proper parking of vehicles. Certain recommendations have been included in this study in accordance with the provisions of IRC SP 12- 2015. Proper implementation of these measures at the selected study locations will result in maximum utilization of the parking space, thus providing a comfortable parking environment for the users.

\section{Acknowledgement}

The authors are thankful to the Municipal Corporation, Tiruchirappalli and Thanjavur cities, and the private parking spaces for giving permission to take up the study.

\section{References}

[1] Kumari Pratibha, (2012)“Analysis of different parking space and its comparison, a thesis submitted to National Institute of Technology, Rourkela.

[2] IRC SP -12 2015, Guidelines for Parking Facilities in Urban Areas.

[3] Subramani T (2012) "Parking Study on Main Corridors in Major Urban Centre": International Journal of Modern Engineering Research, 2 (3) $742-748$

[4] Hsien-Ming (2005) "A location Model for the Allocation of the Off Street Parking Facilities", Journal of the Eastern Asia Society for Transportation Studies, 6, 1344-1353.

[5] Kadiyali L. R. (2013) Traffic Engineering and Transportation Planning, Khanna Publishers, New Delhi. 